\title{
Mass Spectrometry Analysis of Photo-Induced Methionine Oxidation of a Recombinant Human Monoclonal Antibody
}

\author{
Hongcheng Liu, Georgeen Gaza-Bulseco, and Lisa Zhou \\ Protein Analytics, Process Sciences Department, Abbott Bioresearch Center, Worcester, Massachusetts, USA
}

Oxidation of methionine (Met) residues of a recombinant fully human monoclonal antibody after exposure to light was investigated and compared with chemically induced oxidation using tert-butyl-hydroperoxide (tBHP). Met256 and Met432 in the Fc region in the samples exposed to light or incubated with tBHP were oxidized. The Fc mass spectra of the antibody exposed to light showed mainly peaks with a molecular weight (MW) increase of $32 \mathrm{Da}$, however the sample treated with tBHP showed peaks with increase of only $16 \mathrm{Da}$. These results suggested that either oxidation of one Met residue (either Met256 or Met432) catalyzed the oxidation of the second Met residue on the same heavy chain (HC) or Met residues of one $\mathrm{HC}$ were preferentially oxidized when the antibody was exposed to light, while Met256 and Met432 were randomly oxidized when the antibody was incubated with tBHP. (J Am Soc Mass Spectrom 2009, 20, 525-528) (C) 2009 American Society for Mass Spectrometry

$\mathrm{O}$ xidation of Met residues is one of many modifications of recombinant monoclonal antibodies $[1,2]$. The sulfoxide and sulfone side chains of the Met oxidation products are larger and more polar, which may alter protein structure, stability, and biological functions. Oxidation of two susceptible Met residues of a recombinant fully human monoclonal antibody resulted in decreased stability of the $\mathrm{CH} 2$ domain [3] and the binding of this antibody to protein A and protein G [4].

Two Met residues in the $\mathrm{CH} 2-\mathrm{CH} 3$ domain interface of recombinant humanized and fully human IgG1 antibodies were found susceptible to oxidation. The susceptibility of these Met residues was demonstrated by incubating the antibodies in liquid formulation either with $[3,5,6]$ or without $[6,7]$ the addition of a mild oxidizing reagent, tBHP. Lam et al. [7] reported that exposure to high intensity fluorescence light also increased the level of Met oxidation. It was previously observed that Met256 and Met432 (Figure 1) of the antibody used in this study were randomly oxidized on the two HCs when the antibody was incubated with tBHP, which was not the case observed with the accelerated stability sample [6]. It was proposed that either the susceptible Met residues of one $\mathrm{HC}$ of the stability sample were preferentially oxidized or oxidation of the first susceptible Met residue accelerated oxidation of the second Met residue on the same HC.

Address reprint requests to Dr. H. Liu, Protein Analytics, Process Sciences Department, Abbott Bioresearch Center, 100 Research Drive, Worcester, MA 01605, USA. E-mail: liu@abbott.com
In the current study, oxidation of Met 256 (immunogenetics (IMGT) [8] database (Http://imgt.cines.fr): CH215.1) and Met432 (IMGT: CH3-107) of a recombinant fully human monoclonal antibody after exposure to light was investigated and compared with chemically induced oxidation using tBHP. Met 256 and Met 432 were located in the $\mathrm{CH} 2-\mathrm{CH} 3$ interface in close proximity $[8,9]$ and were the focus of this study.

\section{Experimental}

\section{Materials}

The recombinant fully human monoclonal IgG1 antibody was produced by a transfected Chinese hamster ovary $(\mathrm{CHO})$ cell line and purified by multiple chromatography steps (Abbott Bioresearch Center, Worcester, MA). Tert-butyl-hydroperoxide (tBHP) and dithiothreitol (DTT) were purchased from Sigma (St. Louis, MO). Formic acid (FA) was purchased from EMD (Gibbstown, NJ). Endoprotease Lys-C and phenylmethylsulfonyl fluoride (PMSF) were purchased from Roche (Indianapolis, IN). Acetonitrile was purchased from J. T. Baker (Phillipsburg, NJ).

\section{Exposure to Light}

One $\mathrm{mL}$ aliquots of the antibody at $10 \mathrm{mg} / \mathrm{mL}$ in formulation buffer $(5.57 \mathrm{mM}$ sodium phosphate monobasic, $8.69 \mathrm{mM}$ sodium phosphate dibasic, $106.69 \mathrm{mM}$ sodium chloride, $1.07 \mathrm{mM}$ sodium citrate, $6.45 \mathrm{mM}$ citric acid, $66.68 \mathrm{mM}$ mannitol, and $0.1 \%$ 

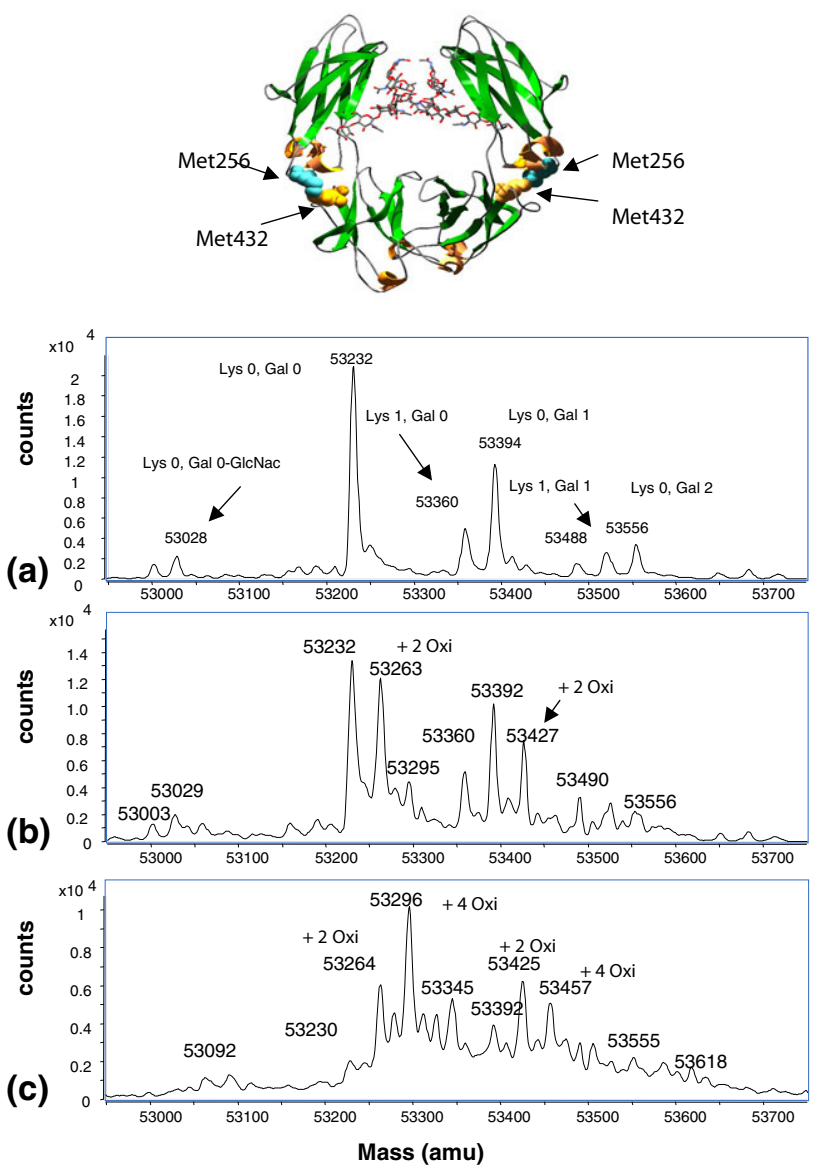

Figure 1. Deconvoluted mass spectra of the Fc fragment before reduction from the samples of the control (a), exposure to light at $\mathrm{ICH}$ suggested level (b), and at four times over-dose (c). Above is a typical human IgG1-Fc structure to show the close proximity of the two Met residues.

polysorbate-20, $\mathrm{pH}$ 5.2) were distributed into clear glass vials, and some of the vials were wrapped in aluminum foil to be used as controls. The vials were then exposed to a light dose of $19460 \mathrm{KJ} / \mathrm{M}^{2}(18.2 \mathrm{~h})$ and four times this dose $(72.8 \mathrm{~h})$ at $300-800 \mathrm{~nm}$ at $25^{\circ} \mathrm{C}$ as defined in the Q1B of ICH guidelines in a light cabinet (Atlas SUNTEST CPS+) with a Xenon lamp filtered through a glass window to mimic indoor daylight (ISO 10,977 ID65).

\section{Incubation with tBHP}

Antibody at $10 \mathrm{mg} / \mathrm{mL}$ in formulation buffer was incubated with $1 \%(\mathrm{vol} / \mathrm{vol}) \mathrm{tBHP}$ at room temperature for $24 \mathrm{~h}$. Residual tBHP was removed using Amicon Ultra-15 centrifugal filters with a MW cut-off of $15 \mathrm{kDa}$ (Millipore, Billerica, MA), and the sample buffer was exchanged to phosphate buffered saline (PBS).

\section{LC-MS Analysis of Fab and Fc Fragments}

The samples were diluted to $1 \mathrm{mg} / \mathrm{mL}$ with PBS and digested with Lys-C at a 1:200 Lys-C: antibody (w:w) ratio at $37^{\circ} \mathrm{C}$ for $30 \mathrm{~min}$. The digestion was stopped with $1 \mathrm{mM}$ PMSF. The samples were analyzed by LC-MS before and after reduction with $10 \mathrm{mM}$ DTT at $37^{\circ} \mathrm{C}$ for $30 \mathrm{~min}$.

An Agilent HPLC and a Q-TOF mass spectrometer 6510 LC/MS system (Santa Clara, CA) equipped with a protein C4 column (Vydac, $150 \times 1 \mathrm{~mm}$ i.d., $5 \mu \mathrm{m}$ particle size, 300 A pore size) were used for MW measurement. Five $\mu \mathrm{g}$ of each sample was loaded at $95 \%$ mobile phase A $(0.08 \%$ FA in Milli-Q water) and $5 \%$ mobile phase B $(0.08 \%$ FA in acetonitrile). After 5 $\mathrm{min}$, proteins were eluted off the column by increasing mobile phase B to $65 \%$ within $35 \mathrm{~min}$. The column was washed using $95 \%$ mobile phase B and equilibrated using $5 \%$ mobile phase B for $10 \mathrm{~min}$. The flow rate was $50 \mu \mathrm{L} / \mathrm{min}$. The column oven was at $60{ }^{\circ} \mathrm{C}$. The mass spectrometer scan range was from $\mathrm{m} / \mathrm{z} 800$ to 2500 with IonSpray voltage of $4500 \mathrm{~V}$ and the source temperature of $350^{\circ} \mathrm{C}$. Mass spectra were deconvoluted using Agilent MassHunter Qualitative Analysis software.

\section{Peptide Mapping}

Samples were denatured with $6 \mathrm{M}$ guanidine hydrochloride in $100 \mathrm{mM}$ Tris, $\mathrm{pH}$ 8.0, reduced with $10 \mathrm{mM}$ DTT at $37^{\circ} \mathrm{C}$ for $30 \mathrm{~min}$ and alkylated with $25 \mathrm{mM}$ iodoacetic acid at $37^{\circ} \mathrm{C}$ for $30 \mathrm{~min}$. The samples were then buffer exchanged to $10 \mathrm{mM}$ Tris, $\mathrm{pH}$ 8.0, using NAP-5 columns (GE Healthcare, Piscataway, NJ). Samples were digested with trypsin (1:20 (w:w) trypsin: antibody ratio) at $37^{\circ} \mathrm{C}$ for $4 \mathrm{~h}$. An Agilent HPLC and a C18 column (Vydac, $250 \mathrm{~mm} \times 1 \mathrm{~mm}$ i.d., $5 \mu \mathrm{m}$ particle size, 300 A pore size) were used to separate and introduce peptides into the Q Star mass spectrometer (Applied Biosystems, Framingham, MA). Twenty $\mu \mathrm{g}$ of each sample was loaded at $2 \%$ mobile phase $B$, and eluted by increasing mobile phase B to $35 \%$ in $140 \mathrm{~min}$. IonSpray voltage was 4200 Volts. Source temperature was $250^{\circ} \mathrm{C}$ and $\mathrm{m} / \mathrm{z}$ was scanned from 250 to 2000 .

\section{Results and Discussion}

\section{Susceptibility of Met Residues in the Fc Region to Oxidation}

Oxidation of Met can result in sulfoxide or sulfone with MW increases of 16 or $32 \mathrm{Da}$ respectively. LC-MS analysis of the peptides containing either Met256 or Met432 from the samples exposed to light or treated with tBHP revealed an additional peak with a MW increase of $16 \mathrm{Da}$. It was confirmed by MS/MS that the MW increase was due to oxidation of Met residues (data not shown). Sulfone as a major oxidation product was ruled out because of no peaks with MW increase of $32 \mathrm{Da}$.

The levels of oxidation were determined by dividing the extracted ion chromatogram (EIC) peak areas of the peptide containing the oxidized Met by the total peak areas of the peptides containing the oxidized and the 
Table 1. Percentage of oxidized Met residues

\begin{tabular}{lcr}
\hline Samples & Met 256 & Met 432 \\
\hline \hline$-80{ }^{\circ} \mathrm{C}$ & 0.1 & 1.4 \\
Control & 1.3 & 2.5 \\
$\mathrm{ICH}$ dose & 16.4 & 21.9 \\
$4 \mathrm{X}$ dose & 73.8 & 78.9 \\
tBHP & 64.7 & 57.8 \\
\hline
\end{tabular}

original Met (Table 1). Met256 and Met432 were oxidized to significant levels after exposure to light. Low levels of oxidation of Met residues in the control suggested that incubation at $25^{\circ} \mathrm{C}$ without exposure to light resulted in Met oxidation. Met oxidation in the sample stored at $-80^{\circ} \mathrm{C}$ was likely due to sample handling. Similarly, Met256 and Met432 were oxidized to significant levels when the antibody was incubated with tBHP.

\section{Distribution of the Oxidized Met Residues in the Samples Exposed to Light}

The samples were digested with Lys-C to cleave between K226 and T227 in the hinge region which resulted in Fab and Fc fragments. Multiple peaks were observed for the Fc due to heterogeneity from incomplete processing of the C-terminal lysine (Lys) and various $\mathrm{N}$-linked oligosaccharides (Figure 1). Peaks with MW increase of 32 Da with the corresponding modifications were observed in the mass spectra from the samples exposed to light at the $\mathrm{ICH}$ suggested level (Figure $1 \mathrm{~b}$ ) and 4 times the dose (Figure 1c). Less intense peaks with a MW increase of 16 Da were also observed.

To understand the distribution of Met oxidation on the two HCs, the samples were analyzed by LC-MS after reduction. Peaks with a MW increase of $32 \mathrm{Da}$ were also at much higher intensities than peaks with a MW increase of $16 \mathrm{Da}$ (Figure 2). This result suggested that either Met256 and Met432 of one HC were preferentially oxidized or

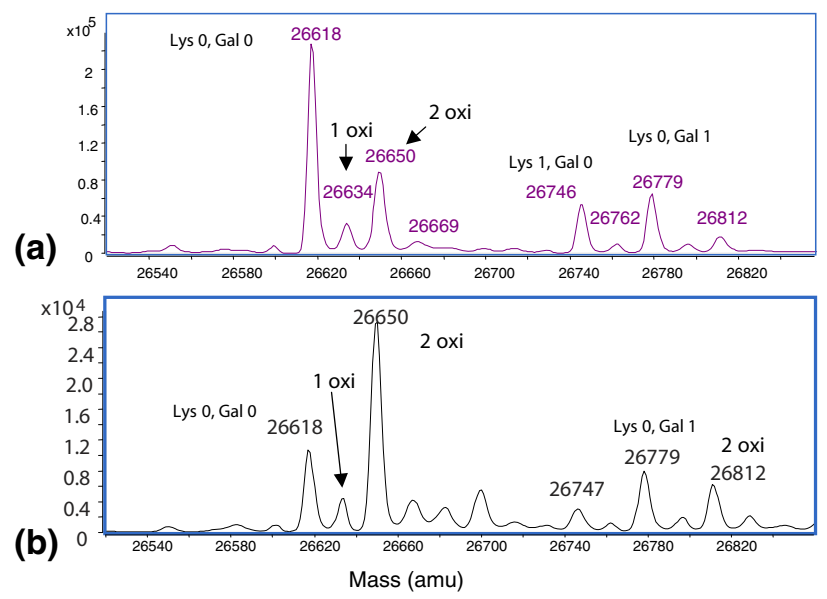

Figure 2. Deconvoluted mass spectra of Fc fragment after reduction $(\mathrm{Fc} / 2)$ from the samples exposure to light at the $\mathrm{ICH}$ suggested level (a) and at four times over-dose (b).
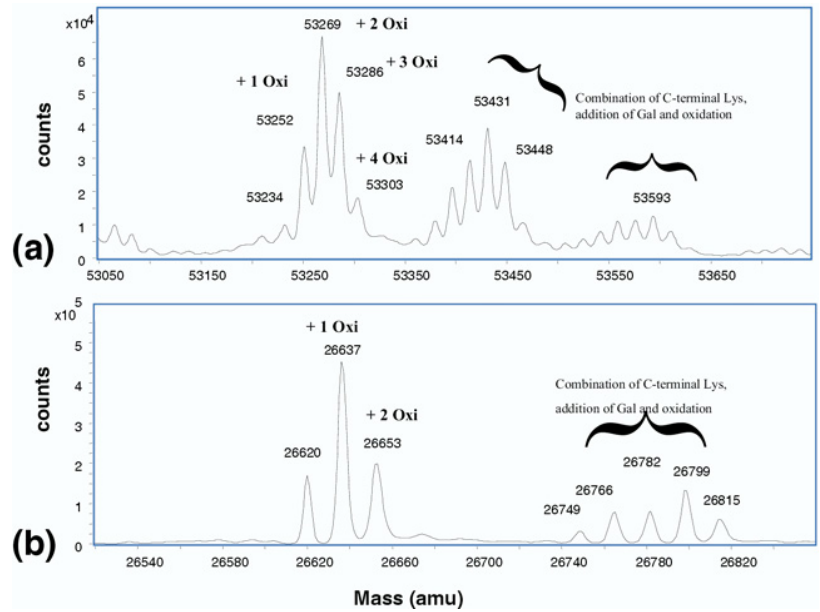

Figure 3. Deconvoluted mass spectra of the antibody oxidized with tBHP before (a) and after (b) reduction of Fc.

oxidation of either Met256 or Met432 accelerated the oxidation of the other on the same HC.

This result supports the hypothesis by Lam et al. [7], which suggested that a singlet oxygen formed from the reaction between molecular oxygen and photo-activated polysorbate-20 reacts with Met to form an intermediate, which reacts with a second Met leading to the formation of two Met sulfoxides. Polysorbate is commonly used in formulations. It was also possible that Met256 and Met432 of one $\mathrm{HC}$ were preferentially oxidized by a light sensitive molecule that binds only to HC because of the asymmetrical nature of IgG antibodies [10].

\section{Distribution of the Oxidized Met Residues in the Sample Incubated with $\mathrm{tBHP}$}

The antibody treated with tBHP was also analyzed. The MWs corresponding to the calculated molecular weights of the $\mathrm{FC}_{\mathrm{C}}$ with various modifications were observed. In addition, MW increments of 16 Da were observed in the mass spectra acquired before (Figure $3 a)$ and after reduction (Figure $3 b$ ), indicating that Met256 and Met432 on the two HCs were randomly oxidized.

\section{Conclusions}

LC-MS is commonly used for monoclonal antibody characterization. This study demonstrated that analysis at different levels (peptide, intact and reduced Fab, Fc) was necessary for obtaining information on the sites and distribution of Met oxidation. Met256 and Met432 were randomly oxidized by tBHP. However, oxidation of these two Met residues was coupled when exposed to light.

Met256 and Met432 are in the $\mathrm{CH} 2-\mathrm{CH} 3$ interface, where residues that are important for the binding to protein A [3], protein G [11], and the neonatal receptor (FcRn) [12] reside. Oxidation of Met256 and Met432 
resulted in significant conformational changes in the $\mathrm{CH} 2$ domain [3], which decreased binding to protein $\mathrm{A}$ and protein G [4]. It would be interesting to study the effect of oxidation on binding to FcRn, which is known to protect antibodies from degradation in vivo [13].

\section{Acknowledgments}

The authors thank Yi Gao for carrying out the photo-stability study.

\section{References}

1. Wang, W.; Singh, S.; Zeng, D. L.; King, K.; Nema, S. Antibody Structure, Instability, and Formulation. I. Pharm. Sci. 2007, 96(1), 1-26.

2. Liu, H.; Gaza-Bulseco, G.; Faldu, D.; Chumsae, C.; Sun, J. Heterogeneity of Monoclonal Antibodies. J. Pharm. Sci. 2008,97(1), 2426-2447.

3. Liu, H.; Gaza-Bulseco, G.; Xiang, T.; Chumsae, C. Structural Effect of Deglycosylation and Methionine Oxidation on a Recombinant Monoclonal Antibody. Mol. Immuno. 2008, 45(3), 701-708; Epub 2007 Aug. 24

4. Gaza-Bulseco, G.; Faldu, S.; Hurkmans, K.; Chumsae, C.; Liu, H. Effect of Methionine Oxidation of a Recombinant Monoclonal Antibody on the Binding Affinity to Protein A and Protein G. J. Chromatogr. B Analyt. Technol. Biomed. Life Sci. 2008, 870(1), 55-62; Epub 2008 Jun. 5.

5. Shen, J. F.; Kwong, Y. M.; Keck, G. R.; Harris, J. R. The Application of tert-Butylhydroperoxide Oxidization to Study Sites of Potential Methionine Oxidization in a Recombinant Antibody; Techniques in Protein
Chemistry VII, Marshak, D. R., Eds, Academic Press: New York, 1996; p.275.

6. Chumsae, C.; Gaza-Bulseco, G.; Sun, J.; Liu, H. Comparison of Methionine Oxidation in Thermal Stability and Chemically Stressed Samples of a Fully Human Monoclonal Antibody. J. Chromatogr. B Analyt. Technol. Biomed. Life Sci. 2007, 850(1/2), 285-294; Epub 2006 Dec. 19.

7. Lam, X. M.; Yang, J. Y.; Cleland, J. L. Antioxidants for Prevention of Methionine Oxidation in Recombinant Monoclonal Antibody HER2. J. Pharm. Sci. 1997, 86(11), 1250-1255.

8. Lefranc, M. P.; Pommie, C.; Kaas, Q.; Duprat, E.; Bosc, N.; Guiraudou, D.; Jean, C.; Ruiz, M.; Da Piedade, I.; Rouard, M.; Foulquier, E.; Thouvenin, V.; Lefranc, G. IMGT Unique Numbering for Immunoglobulin and T cell Receptor Constant Domains and Ig Superfamily C-Like Domains. Dev. Comp. Immunol. 2005, 29(3), 185-203.

9. Deisenhofer, J. Crystallographic Refinement and Atomic Models of a Human Fc Fragment and Its Complex with Fragment B of Protein A from Staphylococcus aureus at 2.9- and 2.8-A Resolution. Biochemistry 1981, 20(9), 2361-2370.

10. Saphire, E. O.; Stanfield, R. L.; Crispin, M. D.; Morris, G.; Zwick, M. B. Pantophlet, R. A.; Parren, P. W.; Rudd, P. M.; Dwek, R. A.; Burton, D. R. Wilson, I. A. Crystal Structure of an Intact Human IgG: Antibody Asymmetry, Flexibility, and a Guide for HIV-1 Vaccine Design. Adv. Exp. Med. Biol. 2003, 535, 55-66.

11. Sauer-Eriksson, A. E.; Kleywegt, G. J.; Uhlen, M.; Jones, T. A. Crystal Structure of the C2 Fragment of Streptococcal Protein G in Complex with the Fc Domain of Human IgG. Structure 1995, 3(3),265-278.

12. Shields, R. L.; Namenuk, A. K.; Hong, K.; Meng, Y. G.; Rae, J.; Briggs, J.; Xie, D.; Lai, J.; Stadlen, A.; Li, B.; Fox, J. A.; Presta, L. G. High Resolution Mapping of the Binding Site on Human IgG1 for FC $\gamma$ RI, FC $\gamma$ RII, FC $\gamma$ RIII, and FcRn, and Design of IgG1 Variants with Improved Binding to the Fc $\gamma$ R. J. Biol. Chem. 2001, 276(9), 6591-6604; Epub 2000 Nov. 28.

13. Roopenian, D. C.; Akilesh, S. FcRn: The Neonatal Fc Receptor Comes of Age. Nat. Rev. Immunol. 2007, 7(9), 715-725. Epub 2007 Aug. 17. 